Document downloaded from:

http://hdl.handle.net/10251/82713

This paper must be cited as:

Payri, R.; Salvador Rubio, FJ.; Viera Sotillo, AA. (2016). Diesel ignition delay and lift-off length through different methodologies using a multi-hole injector. Applied Energy. 162:541550. doi:10.1016/j.apenergy.2015.10.118.

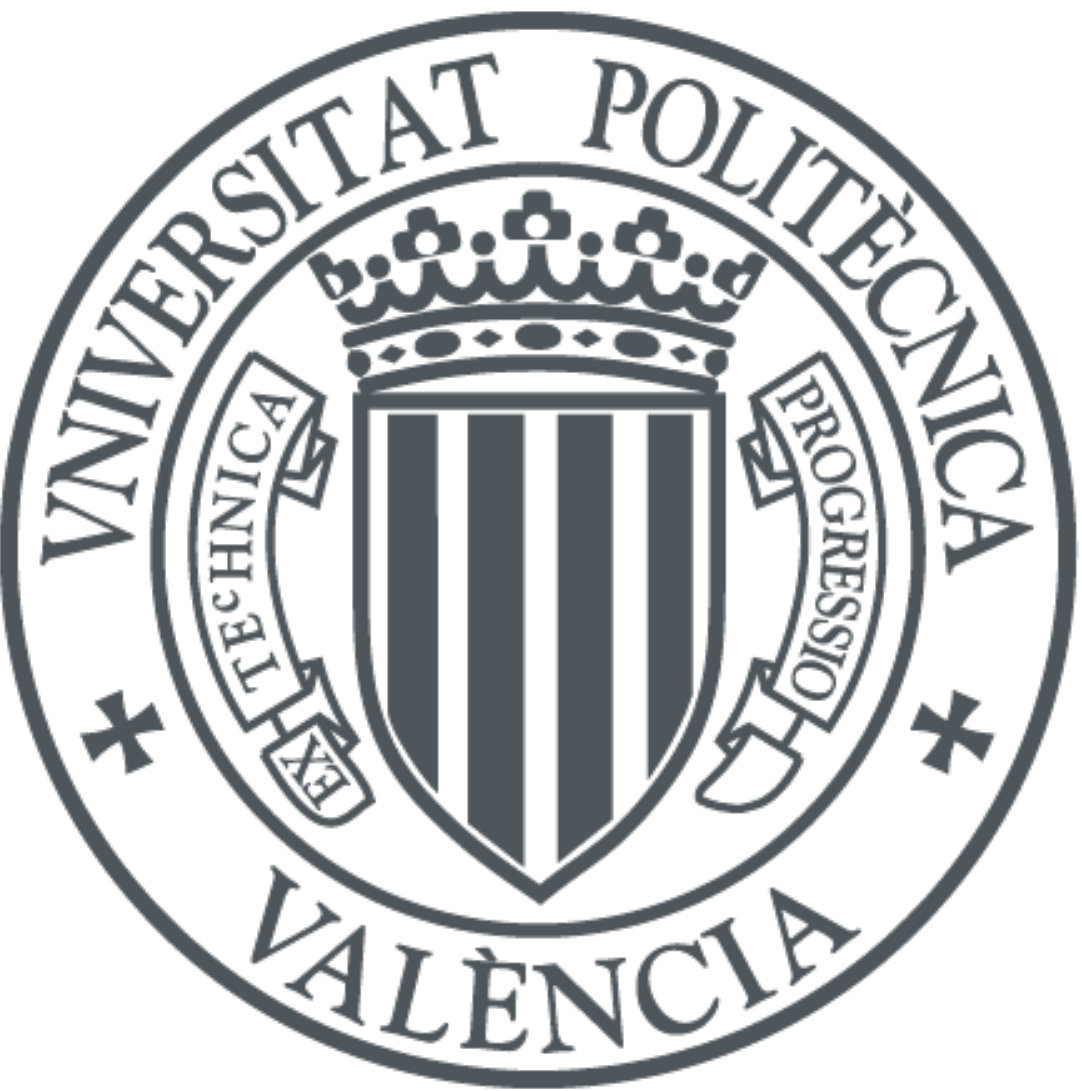

The final publication is available at

http://doi.org/10.1016/j.apenergy.2015.10.118

Copyright Elsevier

Additional Information 


\title{
Diesel ignition delay and lift-off length through different methodologies using a multi-hole injector
}

\author{
Raúl Payri ${ }^{\mathrm{a}, *}$, F.J. Salvador ${ }^{\mathrm{a}}$, Julien Manin ${ }^{\mathrm{b}}$, Alberto Viera ${ }^{\mathrm{a}}$ \\ ${ }^{a}$ CMT - Motores Térmicos, Universitat Politècnica de València, Edificio 6D, 46022, Valencia, Spain. \\ ${ }^{b} C R F$, Sandia National Laboratories, USA.
}

\begin{abstract}
In this paper, lift-off length has been measured via both broadband luminosity and $\mathrm{OH}$ chemiluminescence. In addition, ignition delay has also been measured via broadband chemiluminescence and Schlieren imaging. A 3 orifice injector from the Engine Combustion Network (ECN) set, referred to as Spray B, and a single component fuel (n-dodecane) was used. Experiments were carried out in a constant flow and pressure facility, that allowed to reproduce engine-like thermodynamic conditions, and enabled the study to be performed over a wide range of test conditions with a very high repetition rate. Data obtained was also compared with results from a single orifice injector also from the Engine Combustion Network, with analog orifice characteristics (90 micrometer outlet diameter and convergent shape) and technology as the injector used. Results showed that there is good correlation between the ignition delay measured through both methodologies, that oxygen concentration and injection pressure plays a minor role in the ignition delay, being ambient temperature and density the parameters with the highest influence. Lift-off length measurements showed significant differences between methodologies. Minor deviation was observed between injectors with different nozzle geometry (seat inclination angle), due to temperature variations along the chamber, highlighting the importance of temperature distribution along combustion vessels. Empirical correlations for lift-off and ignition delay were calculated, underlining the effect of the conditions on the parameters studied. Coefficients of the correlations were compared with results for the single orifice injector, this showed that variations of test conditions have the same impact on ignition delay and lift-off length regardless the nozzle orifice configuration.
\end{abstract}

Keywords: Diesel injection, Ignition, Lift-off length, Schlieren

\section{Introduction}

Pollutant emissions have been a major concern for diesel engines for over a decade. Driven by climate change and environmental effects, stricter emission regulations push the engine designers to look for solutions to build cleaner engines. Many studies have shown that optimized mixing of the injected fuel with the ambient gases was key to reducing pollutant emissions [13]. Although Computational Fluid Dynamic (CFD) simulation results are of great help when

\footnotetext{
*Corresponding author. E-mail address: rpayri@mot.upv.es .
} 
designing thermal engines [4-6], experimental data are crucial not only to validate these models, but also to define the boundary conditions of the problem. One particularly interesting aspect is the difference in flow and combustion for sprays interacting with one another or in isolation [7]. A few studies have been carried out to compare different spray spacing [8, 9] or the differences between multi- and single-hole nozzles [10]. The former studies have been performed in an optical engine, while the latter was done in an optically accessible vessel. The level of detail achieved by the investigation from Jung et al. [10] goes well beyond what the Chartier's and Lequien's group has been able to extract. For instance, the quiescent and nearly constant conditions in the spray chamber allowed the authors to understand the detailed effects of low-lift needle motion on spray opening and evaporation. The authors suggested that these observations should impact global mixing and combustion processes under reacting conditions.

Optically accessible vessels with high-pressure and temperature capabilities are necessary tools to study the development and combustion processes of fuel sprays into ambient conditions relevant to thermal engines. The Engine Combustion Network (ECN) is an international collaboration group whose objective is to establish a library of reliable experimental data appropriate for model validation, and to leverage the scientific understanding of spray combustion at engine relevant conditions [11]. For this purpose, the experimentalists use stateof-the-art optically accessible chambers in which nominally identical injectors are mounted to generate sprays under tightly controlled conditions [12, 13]. As part of the scope of research, the ECN uses single and multi-hole injectors with nominally identical specifications [14]. The study by Jung et al. [10] mentioned earlier compared the multiple and single orifice injectors from the ECN in an optically accessible vessel under inert, evaporative conditions. Yet, a follow-up study remains to be performed where the same conditions are analyzed under reacting conditions, in order to confirm the expectations based on the non-reacting tests.

In this work, a three hole injector (Spray B) from the ECN was used. This injector has a particularity as the three holes are not equally spaced, so that one of the orifice would be more isolated from the others to offer better optical access. A similar injector, featuring an axiallydrilled orifice (Spray A), and also from the ECN, has been used as comparison to the three-hole version. The geometry and characteristics of both these injectors are well known and available on the ECN website [11]. Because of the relative simplicity of Spray A (single-hole), highly detailed experiments have been performed on this injector and spray system, but the geometry of Spray B comes closer to the multi-hole injectors found in production engines, thus driving significant interest from experimental and numerical researchers. The sprays have been injected in a high-pressure and high-temperature constant-pressure flow facility (CPF). This facility allows performing experimental studies simulating the conditions found in the combustion chamber of current compression ignition engines in terms of temperature, pressure or oxygen concentration. The tests performed in this study focused primarily on measuring the ignition delay and the flame lift-off length under a range of conditions. The parametric variation carried out in this study concerned chamber pressure (gas density), gas temperature, ambient oxygen concentration and fuel injection pressure. Several optical diagnostics have been used to measure ignition delay and lift-off length: Ignition delay detected by high-speed broadband flame chemiluminescence, as well as with high-speed schlieren imaging. Quasisteady lift-off length was measured via $\mathrm{OH}$-chemiluminescence with an intensified camera, 


\begin{tabular}{|c|c|c|c|}
\hline \multicolumn{4}{|c|}{ Nomenclature } \\
\hline$\Delta p_{i n j}$ & Fuel pressure drop in nozzle orifice & CFD & Computational Fluid Dynamics \\
\hline$\Delta y$ & Total intensity increment & $\mathrm{CPF}$ & Constant-pressure flow (facility) \\
\hline$\rho_{a m b}$ & Ambient density & CWL & Center wavelength \\
\hline$\rho_{\text {fuel }}$ & Fuel density & $\mathrm{D}_{o}$ & Orifice diameter \\
\hline$p_{i n j}$ & Injection pressure & ET & Energizing time \\
\hline$T$ & Ambient Temperature & ID & Ignition delay \\
\hline $\begin{array}{l}y \\
k \text {-factor }\end{array}$ & $\begin{array}{l}\text { Total intensity } \\
\text { Nozzle orifice conicity factor }\end{array}$ & LOL & Lift-off length \\
\hline$A, a, b, c, d$ & Empirical correlations parameters & $\mathrm{O}_{2} \%$ & Ambient oxygen concentration \\
\hline ASOE & After start of energizing & SoC & Start of combustion \\
\hline ASOI & After start of injection & SSI & Second stage ignition \\
\hline
\end{tabular}

while time-resolved flame stabilization was measured with a high-speed camera acquiring broadband flame luminosity.

This paper has been divided into four sections. Following this introduction, the experimental facilities are detailed, along with descriptions of the optical setups and experimental methods used in this work. The results are presented next, with the comparisons to the singleorifice from the ECN. The results are discussed in this same section, and correlations are proposed to predict ignition delay and lift-off length with the three hole nozzle, compared to the correlation coefficients from the single orifice experimental results. Finally, the last section presents the conclusions of this study.

\section{Experimental setup and procedures}

The following section briefly presents the experimental chamber and injection equipment used to carry out the experiments, followed by the test matrix, where test conditions are summarized, concluding with the optical setup and image processing methodology employed.

\subsection{Spray chamber and injection system}

According to the convention used by Baert et al. [15], an optically accessible constant-pressure flow (CPF) test chamber was used. This chamber is not only able to reproduce the thermodynamic conditions of a Diesel engine, but also, compared to other high-pressure hightemperature vessels [15-17], has the unique feature of presenting nearly quiescent and steady thermodynamic conditions within the chamber, allowing to test wide range of conditions and multiple repetitions without the penalty of long testing periods [12, 13].

The facility can be divided into four parts: compressors, heaters, test vessel and control system. High pressure gas, stored in reservoirs, enters the chambers through a $30 \mathrm{~kW}$ electric heating system, rising the temperature to the desired level. Then the hot gases exit the vessel 
and are cooled to be recirculated to the compressors or thrown to the atmosphere. When recirculating the gases, its possible to control the oxygen concentration in the test section. The control system is a closed loop PID that adjusts both the pressure in the chamber, and the power output of the heaters. To reduce temperature differences within the test chamber, the vessel has a double wall configuration: the external wall acts purely as a structural element, while the inner wall is thinner and its surrounded with an insulation layer, to avoid heat loss towards the outer shell.

The injector utilized for the experiments is part of the ECN dataset (ref: \#0211200). The internal geometry and hydraulic characteristics have been thoroughly investigated and can be found on the ECN web page [11]. Following the ECN guidelines, a single component fuel (n-Dodecane) was used.

The injection system employed consists of commercial available components: high pressure volumetric Bosch $\mathrm{CP} 3$ pump driven by an electric motor and a common rail with pressure regulator controlled by a PID system. The injector is connected to the common rail with a high pressure line, and inserted in the vessel through a holder that has a continuous flow of ethylene glycol running in a parallel circuit, the fluid's temperature in set to keep the injector's nozzle tip temperature constant [18].

\subsection{Test matrix}

Test conditions are summarized in Table 1 It includes Spray A target condition $(T=900 \mathrm{~K}$, $\left.\rho_{a m b}=22.8 \mathrm{~kg} / \mathrm{m}^{3}, p_{i n j}=150 \mathrm{MPa}, O_{2}=15 \%\right)$ as well as parametric variations following the ECN recommendations [11] with additional ambient conditions.

Table 1: Test conditions.

\begin{tabular}{lll}
\hline Parameter & Values & Units \\
\hline Fuel & $\mathrm{n}$-Dodecane & - \\
Nominal orifice diameter $\left(\mathrm{D}_{o}\right)$ & 90 & $\mu \mathrm{m}$ \\
$k$-factor & 1.5 & - \\
Energizing time & 2.5 & $\mathrm{~ms}$ \\
Tip temperature & 363 & $\mathrm{~K}$ \\
Gas density $\left(\rho_{a m b}\right)$ & $7.6^{*}-15.2^{*}-22.8$ & $\mathrm{~kg} / \mathrm{m}^{3}$ \\
Gas temperature $(T)$ & $800-820^{* *}-900$ & $\mathrm{~K}$ \\
Injection pressure $\left(p_{i n j}\right)$ & $50-100-150$ & $\mathrm{MPa}$ \\
Oxygen concentration $\left(\mathrm{O}_{2} \%\right)$ & $13-15-17-19-21$ & $\%(\mathrm{vol})$. \\
\hline${ }^{*}$ Only for $21 \%$ oxygen concentration and $900 \mathrm{~K}$. \\
** Only for $15 \%$ and $21 \%$ oxygen concentration.
\end{tabular}

\subsection{Ignition delay}

During the Diesel combustion, there are certain chemical reactions that produce molecules (radicals) in an excited state. These radicals may go to more stable energetic levels, emitting 
light during this process. This phenomenon (chemiluminescence) can be used for the determination of Diesel ignition. Dec and Espey [19] showed that $\mathrm{CH}$ radicals are excellent markers for the characterization of the first phase Diesel combustion (cool flame), and that second stage ignition (SSI) can be characterized by the appearance of $\mathrm{OH}$ radicals. Accordingly, ignition delay is typically defined as the time between the start of injection and second stage ignition. Different methodologies have been presented [20-22] in order to avoid the use of intensified ICCD cameras to detect ignition delay. Two different methods using high speed cameras have been employed in this study: Broadband chemiluminescence [13] and Schlieren imaging [20]. Details about the optical setups are presented in Table 2

Table 2: Detailed optical setups.

\begin{tabular}{|c|c|c|c|}
\hline & $\begin{array}{l}\text { Schlieren } \\
\text { imaging }\end{array}$ & $\begin{array}{l}\text { Broadband } \\
\text { chemilum. }\end{array}$ & $\begin{array}{l}\mathrm{OH}^{*} \\
\text { chemilum. }\end{array}$ \\
\hline Camera & Phantom - V 12 & Photron SA-X2 & Andor -iStar \\
\hline Sensor type & CMOS & CMOS & ICCD \\
\hline Lens & $100 \mathrm{~mm}$ & $100 \mathrm{~mm}$ & $100 \mathrm{~mm}$ - U.V. \\
\hline Diaphragm & $4 \mathrm{~mm}$ & - & - \\
\hline Filter & $\leq 600 \mathrm{~nm}$ & $\leq 600 \mathrm{~nm}$ & 305-315 nm CWL \\
\hline Frame rate & $105.6 \mathrm{kfps}$ & $55 \mathrm{kfps}$ & $\begin{array}{l}1 \text { frame/ } \\
\text { injection }\end{array}$ \\
\hline Shutter time & $2 \mu \mathrm{s}$ & $0.37-1.25 \mu \mathrm{s}^{*}$ & $2.5 \mathrm{~ms}$ \\
\hline Repetitions & 10 & 10 & 10 \\
\hline Pixel-mm & 6.7 & 7.0 & 8.9 \\
\hline
\end{tabular}

${ }^{*}$ Exposure was set to lower value only when saturation was too high.

\subsubsection{Schlieren imaging}

Schlieren imaging relies on the deviation of light rays from their original paths consequence of them traveling through a non uniform medium [23], in this case a Diesel spray injected in a hot atmosphere. Density gradients between fuel and ambient gases allow the Schlieren technique to detect the boundary of the spray, and by studying the variation of the intensity withing that spray boundary (in pixel counts) it is possible to determine the ignition delay [20]. The Schlieren setup, presented in Fig. 1, is thoroughly described by Pastor et al. [24], consists of a point light source $(2 \mathrm{~mm})$ located at the focal distance of a parabolic mirror $(610 \mathrm{~mm})$, with an incident angle minimized in order to reduce beam straightening, the light source used is a white-light $150 \mathrm{~W}$ halogen lamp. The now parallel light beams, colored yellow in the Fig. 1. travel trough the testing section, gathering the information of the spray in meanings of deviation caused by density gradients. This deviated light (colored orange) is then collected by a $150 \mathrm{~mm}$ lens with a focal distance of $450 \mathrm{~mm}$, where a diaphragm with a cut-off diameter of $4 \mathrm{~mm}$ is located. To reduce luminosity from combustion, a bandpass filter of $\leq 600 \mathrm{~nm}$ was used. Details of the optical setup used are presented in Table 2 .

To obtain ignition delay from the Schlieren imaging, the same approach used by Benajes et al. [20] was used. The processing methodology is briefly explained below: 


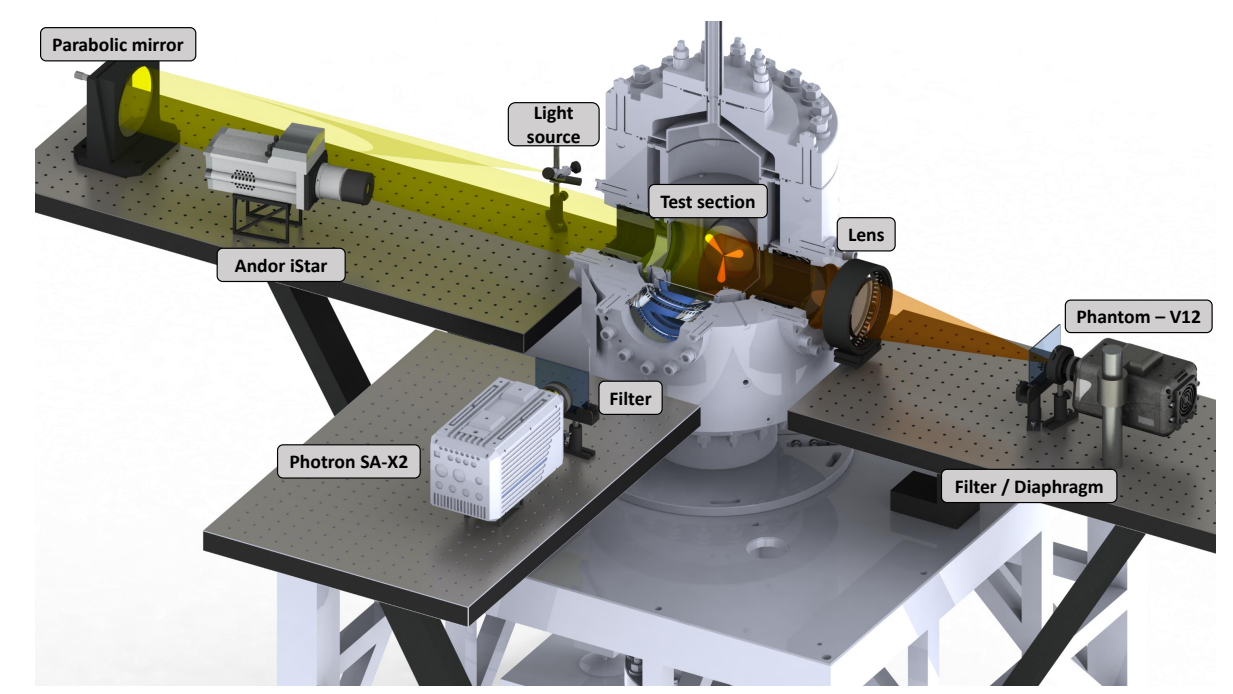

Fig. 1: Optical setup used. Photron SA-X2 for broadband chemiluminescence. Andor iStar ICCD camera equipped with $310 \mathrm{~nm}$ center wavelength (CWL) filter for quasi-steady LOL. Phantom - V12 for schlieren imaging.

- Background correction: Images acquired tend to have a characteristic background pattern (Fig. 2), due to the temperature (i.e. density) inhomogeneities in the test section. Although this background is moving because of the continuous flow (CPF facility), between two consecutive images it can considered steady, due to the differences between flow and spray velocities. Background correction is applied by subtracting pixels that were not within spray boundaries in the previous image.

- Spray boundaries: Following the methodology described by Siebers [16], to obtain spray boundaries binarization threshold is defined as $5 \%$ of the dynamic range for each image.

- Total intensity $(y)$ : Defined as the sum of the counts pixels that are part of the spray.

- Total intensity increment $(\Delta y)$ : Obtained by tracing the difference of the total intensity $(y)$ between two consequent images. Analyzing the total intensity increment signal $(\Delta y)$, for example as presented in the left graph of Fig. 3 , it is possible to obtain parameters such as start of cool flame, or first stage ignition due to the disappearance effect, followed by second stage ignition (SSI) as a local maximum right after first stage ignition, because of the rapid expansion and darkening of the spray as can be observed in Fig. 2.

For a more detailed information on the processing, please refer to [20].

\subsubsection{Broadband chemiluminescence ID}

As stated before, combustion produces light by the process of chemiluminescence. This light can be seen and recorded as a signal through time, and because this phenomenon is directly related to combustion, there is a link between chemiluminescence and ignition delay [21]. Using a high-speed camera (Photron SA-X2), equipped with a Zeiss $100 \mathrm{~mm}$ lens, broadband chemiluminescence was observed through the frontal window of the test section, as seen in Fig. 1. An example of the images obtain through this setup are presented in the right part of Fig. 2, the histogram of intensity has been stretched to ease the visualization of ignition. Previous setups by other authors [13, 20] used long shutter times, increasing the sensitivity of the 
Raúl Payri, F.J. Salvador, Julien Manin, Alberto Viera; Diesel ignition delay and lift-off length through different methodologies using a multi-hole injector. Applied Energy, 2015, 162, 541-550.
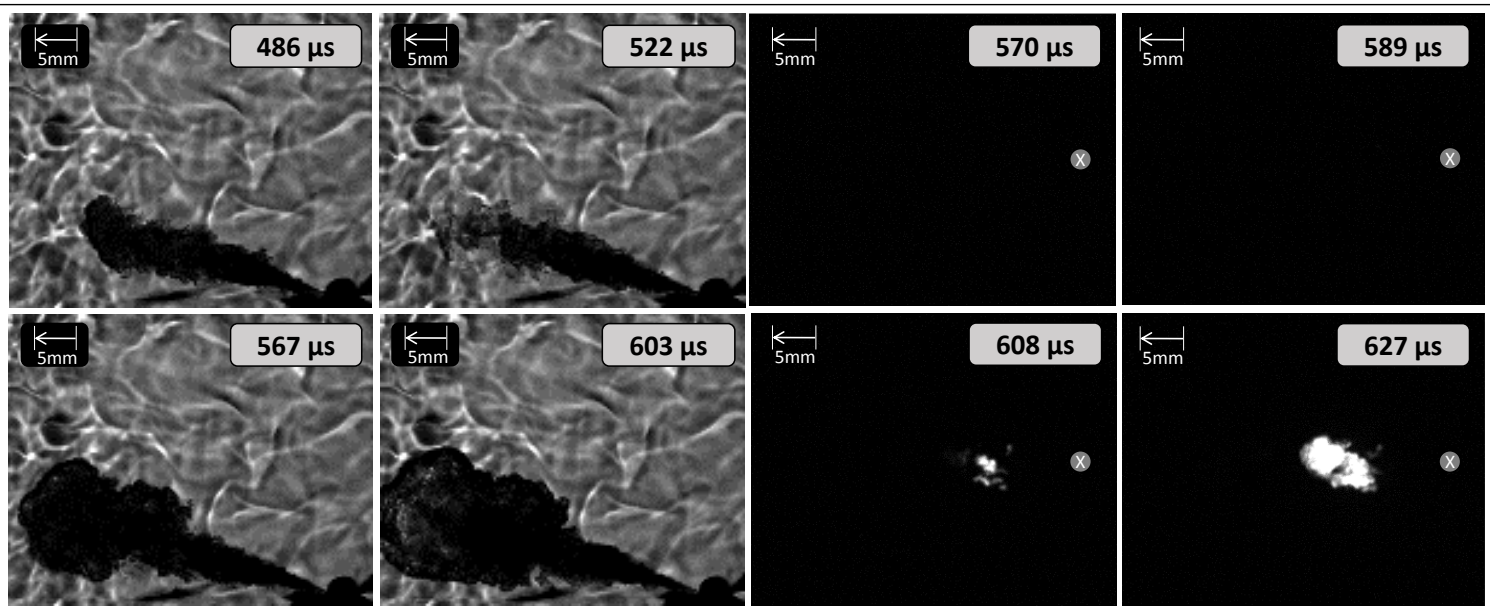

Fig. 2: Ignition sequence seen by Schlieren images (left) and broadband chemiluminescence (right), please note different time scales, both after start of energinzing (ASOE). The arrow on the top left corner of each image correspond to the direction in which the spray of the orifice of interest is traveling. Circle symbolize injector's tip location. $\left(T=900 \mathrm{~K}, \rho_{a m b}=22.8 \mathrm{~kg} / \mathrm{m}^{3}, \mathrm{O}_{2} \%=21 \%, p_{i n j}=150 \mathrm{MPa}\right)$.

camera and allowing to record minor variations in light emissions. But this created a problem to measure broadband lift-off length in the same injection event, because too much saturation was observed caused by the light emitted from the flames of the 3 sprays and reflections on the background, thus a low shutter time was used, as can be seen in Table 2

Because of a short shutter time, a minor modification was done to the processing of the images. Originally, as explained by Lillo et al. [21], a region of interest near the expected lift-off length (or far from soot luminosity) is virtually drawn. Then the maximum intensity in this region is traced per time step (for each image). Lastly, following ECN guidelines [11], ignition delay is the time of the image with $50 \%$ of the intensity of high temperature chemiluminescence. In this case, because the camera was setup to be less sensitive to light, ignition delay is defined as the time when the intensity of the image was above a very small threshold $\left(0.6^{\circ} \%\right.$ of the maximum digital level, just above background noise). The right side of Fig. 3 . represents the maximum intensity recorded as a function of time for several repetitions.
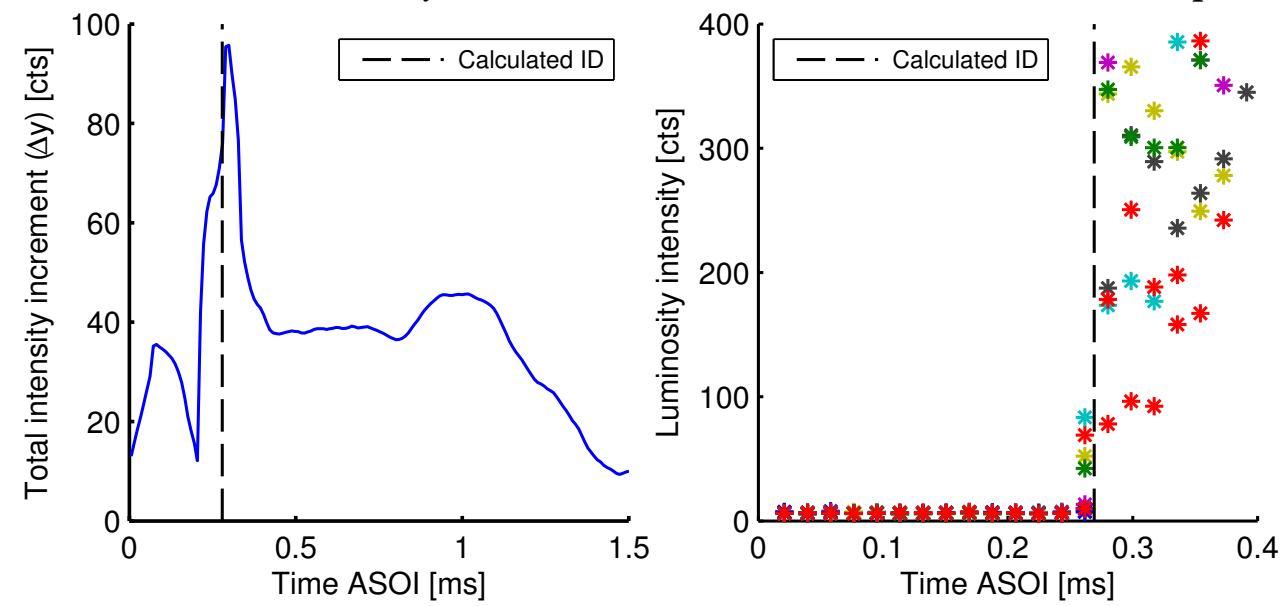

Fig. 3: Example of the processing for Schlieren imaging (left) and for ignition delay broadband chemiluminescence (right). On the left is the symmetric derivative [25] of the total intensity $y$ of the spray is presented. On the right is the luminosity intensity for broadband where each color represents a repetition. Black dashed line is the ignition delay for each plot. $\left(T=900 \mathrm{~K}, \rho_{a m b}=22.8 \mathrm{~kg} / \mathrm{m}^{3}, \mathrm{O}_{2} \%=21 \%, p_{i n j}=150 \mathrm{MPa}\right)$. 


\subsection{Lift-off length}

Flame lift-off is defined as the distance from the injector tip to the stabilized high-temperature reaction zone, and plays an important role in the combustion and emission processes, being an indicator of the time that fuel and air are mixing before reaching the combustion region [26, 27].

\subsection{1. $\mathrm{OH}^{*}$ chemiluminescence}

$\mathrm{OH}^{*}$ chemiluminescence is used to measured lift-off length because it is known to appear under high temperature combustion [28], but it was Higgins and Siebers [29] who first measured LOL using an intensified cameras fitted with an interferometric filter, concluding that $\mathrm{OH}^{*}$ was a good indicator to measure the lift-off length. As seen in Fig. 2, an ICCD Andor iStar camera fitted with a $100 \mathrm{~mm} \mathrm{f} / 2.9 \mathrm{UV}$ lens equipped with a $310 \pm 5 \mathrm{~nm}$ CWL filter is used, following the ECN standard methodology [11, 26]. A constant intensifier gating time between 2.0 and $4.5 \mathrm{~ms}$ was used, in order to capture an average image of the injection event and reduce shot-to-shot deviation. Post-processing was done using the Siebers and Higgins approach [26]. After filtering the image with a $3 \times 3$ pixel mean filter, the flame is divided through its axis into a top and bottom profiles, for each axial position the maximum intensity is traced as shown in Fig. 4. The lift-off length is the averaging of the distances between nozzle tip and the first value above $50 \%$ of the intensity peak for each profile.
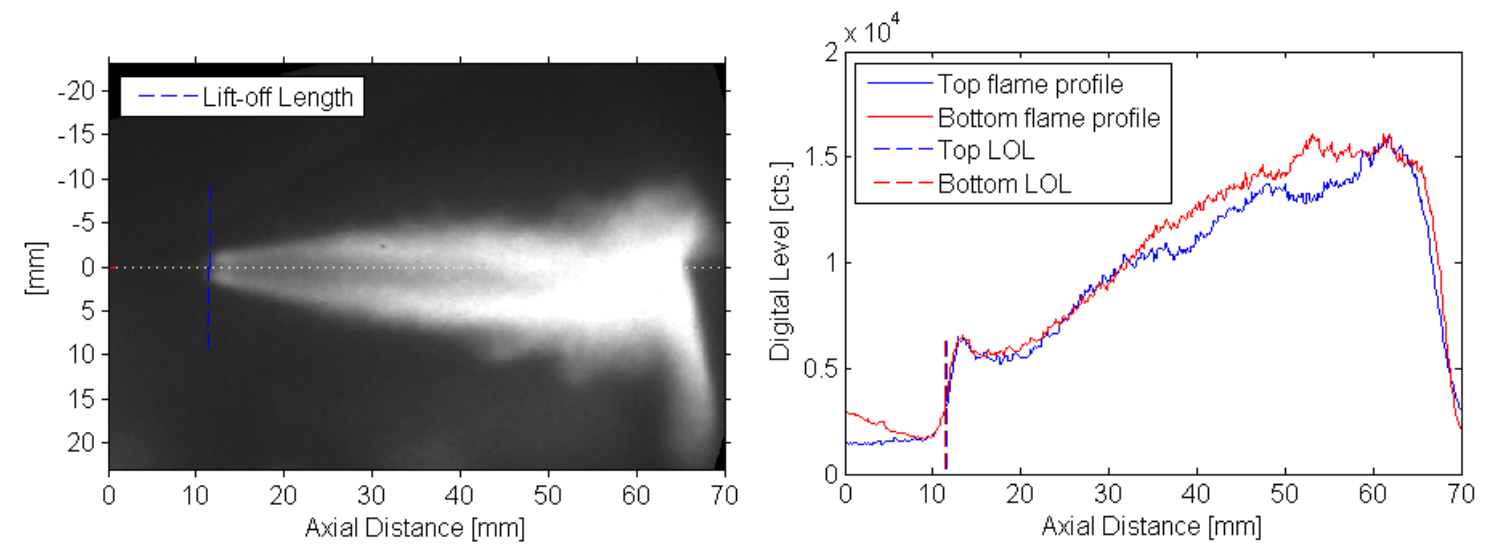

Fig. 4: Lift-off length by $\mathrm{OH}^{*}$ chemiluminescence. Left: sample image from the ICCD Andor iStar, dashed blue line represents the LOL with a 50\% thresold. Right: intensity profiles for both top (blue) and bottom (red) portions of the flame, dashed lines of the same colors correspond to LOL measured with a $50 \%$ of the intensity peak. $(T=$ $\left.900 \mathrm{~K}, \rho_{a m b}=22.8 \mathrm{~kg} / \mathrm{m}^{3}, \mathrm{O}_{2} \%=21 \%, p_{i n j}=150 \mathrm{MPa}\right)$.

\subsubsection{Broadband chemiluminescence $L O L$}

As with ignition delay, it is possible to measure the lift-off length with broadband chemiluminescence of the flame. As seen by Dec and Espey [19], $\mathrm{OH}^{*}$ chemiluminescence has its maximum intensity for a wavelength of $310 \mathrm{~nm}$, whereas soot emission is above $340 \mathrm{~nm}$. Therefore, in broadband imaging the most predominant light recorded is the one radiated by soot, and as explained in the literature [19, 30] soot is present in downstream portions of the jet under most Diesel conditions. To avoid confusion and minimize this difference, lift-off length was defined as the distance between the orifice exit and the first pixel with an intensity above a relatively low intensity threshold (3.5\% of the digital level) just above background noise and 
flare. To prevent liquid scattering from affecting the measurement, an offset was defined, so only the region downstream of the maximum liquid penetration was taken into account during the processing. In order to obtain a single value, the time-resolved LOL measurements were averaged between 3 and $4 \mathrm{~ms}$ after start of injection (ASOI), which corresponded to the period during which the flame was stable across the different conditions.

\section{Results and discussion}

In this section, all results obtained are presented, effect of tested conditions on the parameters studied are discussed, also including differences observed between the single orifice nozzle and the injector used. Additionally, due to the wide range of conditions tested, empirical correlations that relate the impact of tested conditions on these parameters are calculated and also compared with the single orifice nozzle.

\subsection{Ignition delay}

In order to help understand the influence of the parametric variations in the ignition delay, first a comparison of the two methods used is presented, following only by the results of the delay obtained with broadband chemiluminescence (density variations were only recorded through this methodology). Fig. 5 shows all the ignition delays calculated for all conditions tested, Note that color gradients correspond injection pressure variations, being the darkest color 150 $\mathrm{MPa}$ and the lightest $50 \mathrm{MPa}$. Some considerations can be made:

- High temperature conditions (900 K) showed excellent agreement between methodologies.

- Ignition delays obtained through Schlieren imaging tend to be higher than those from broadband chemiluminescence. This is due to the fact that the processing methodology used in broadband ID is sensitive to light emission from the flame, on the other hand, Schlieren depends on the intensity of the pixels and its variations, as explained before.

- When reaction occurred rapidly (for example, high temperature conditions), results showed better agreement. So the sensitivity of the broadband processing had a minor effect for shorter ignition delays. On the other hand, with higher delays, as light was captured by the broadband camera in a very early stage of the start of ignition, Schlieren methodology needs the combustion to occur and the spray to expand, in other words, needs the whole phenomenon of disappearance/re-appearance to occur, and at lower temperature this process is slower so the processing lags compared to broadband in detecting the ignition delay. So reaction rate plays an important role in the differences obtained for higher ignition delays.

- Both methodologies capture second stage ignition in different ways, so differences are expected. Still results are in very good agreement for conditions tested, although is not clear whether good agreement will continue for higher ignition delays (i.e. lower temperatures). 
Raúl Payri, F.J. Salvador, Julien Manin, Alberto Viera; Diesel ignition delay and lift-off length through different methodologies using a multi-hole injector. Applied Energy, 2015, 162, 541-550.

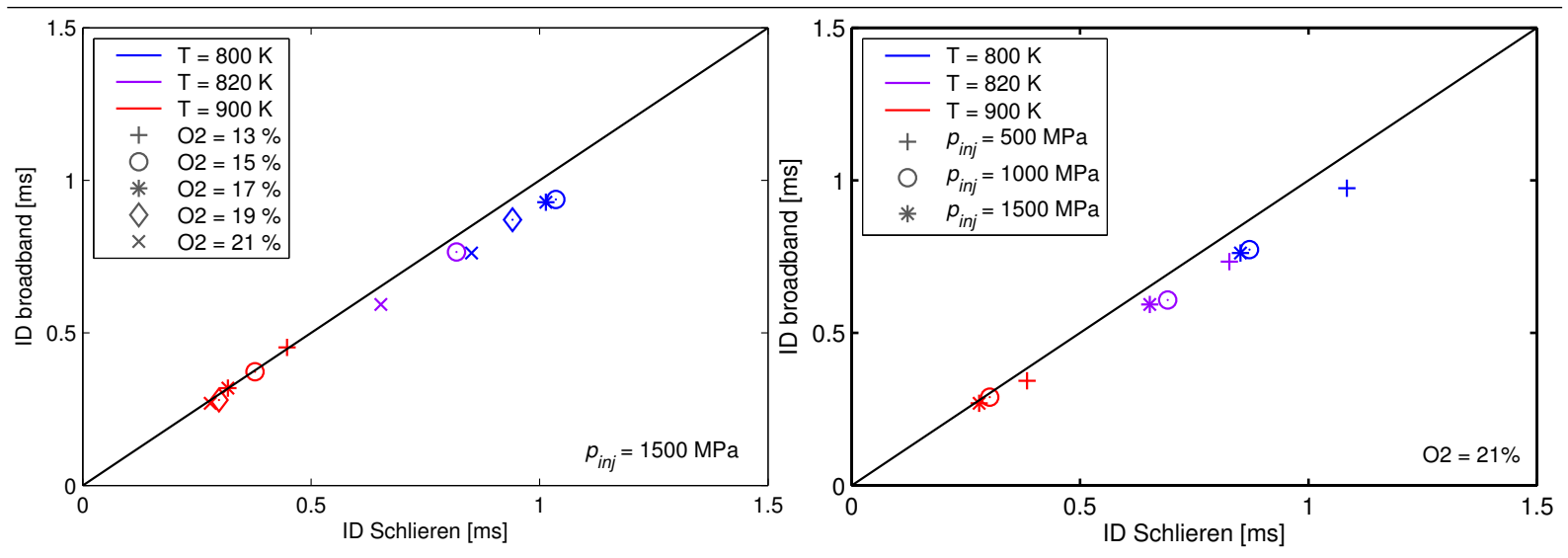

Fig. 5: Ignition delay results for all conditions tested. Horizontal axis correspond to Schlieren imaging and vertical axis to broadband chemiluminescence. Left plot corresponds to variations of oxygen concentration, while the right plot to injection pressures. Black solid line represents $y=x$.

\subsubsection{Impact of operating conditions on ignition delay}

Experimental results by multiple authors [27, 29, 31-34] have shown the effect of oxygen concentration, ambient temperature, density and injection pressure on ignition delay. As theoretically explained by Petrucci et al. [35], increasing oxygen concentration and ambient temperature accelerate oxidation reactions, resulting in a reduction in ignition delay. On the other hand, injection pressure and ambient density play a significant role in the mixing process, which is directly link to the time when combustion occurs. Experimental results have shown that increasing chamber density and injection pressure resulted in a decrease of the ignition delay.

Knowing that both methodologies showed very similar results, is possible to isolate how parametric variations of ambient conditions affect ignition delay for this injector, as shown in Fig. 6. The left plot shows to that oxygen concentration and injection pressure play a minor role on the ignition delay, ambient temperature being the most dominant factor. On the right plot of Fig. 6, although density variation was only studied for a fixed oxygen concentration and only one ambient temperature, it can be observed that plays an important role, because moving from 7.6 to $22.8 \mathrm{~kg} / \mathrm{m}^{3}$ the ignition delay was reduced by almost $40 \%$.
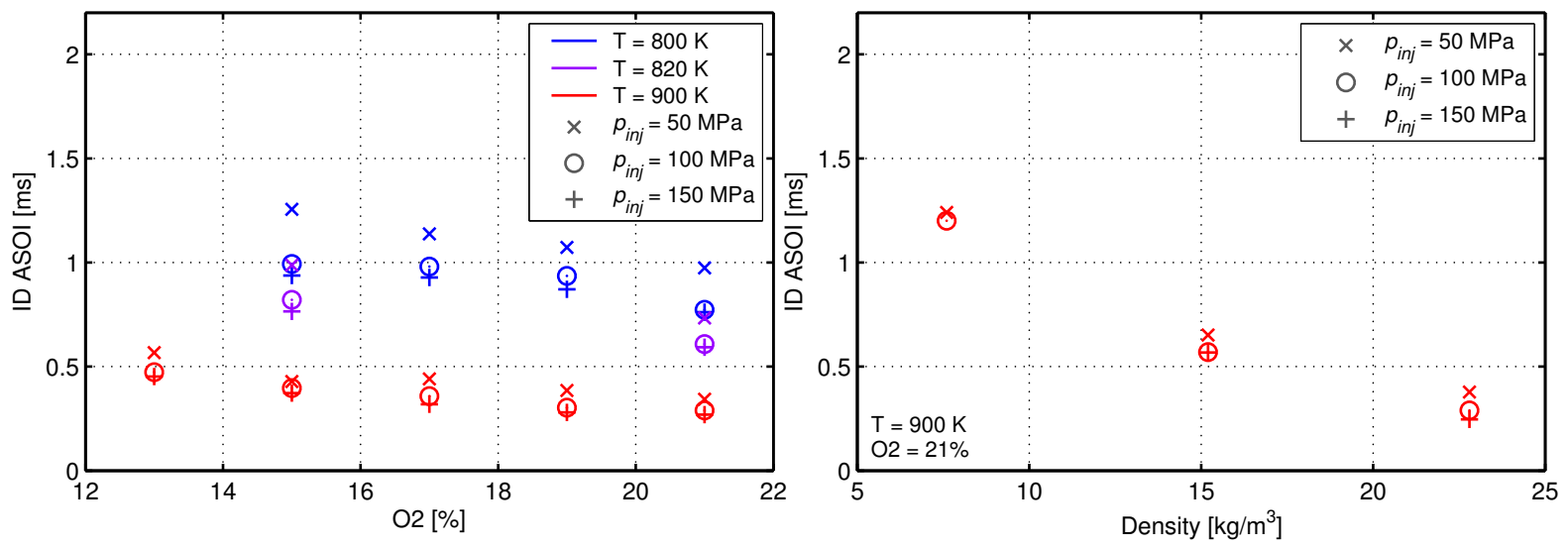

Fig. 6: Effect of ambient conditions on ignition delay. On the left the effects of oxygen concentration, temperature and injection pressure is shown. On the right the effect of density. 


\subsection{Lift-off Length}

Following the procedure previously described, a comparison between the $\mathrm{OH}^{*}$ and broadband chemiluminescence imaging methodologies used is first presented, in order to discuss each method. Then, to observe the effect of parametric variations of ambient conditions on the lift-off length, only the results of $\mathrm{OH}^{*}$ chemiluminescence will be used, being the standard methodology of the ECN and the most widely used technique. In Fig. 7 results of both imaging setups are presented, the horizontal axis corresponds to $\mathrm{OH}^{*}$ chemiluminescence, and vertical axis is broadband chemiluminescence, with solid black line which correspond to $y=x$. From the figure, some observations can be made:

- Trend showed that broadband LOL is mostly higher than $\mathrm{OH}^{*}$ chemiluminescence LOL. This is because broadband imaging captures mostly the light emitted by soot, and as stated before, soot is present in downstream portions of the jet, so only for conditions where $\mathrm{OH}^{*}$ chemiluminescence and soot luminosity occur near the same region, results would agree, probably under ambient temperatures above the ones tested. This same effect was observed also by Bazyn and Koci [36].

- $\mathrm{OH}^{*}$ chemiluminescence imaging is a widely proven methodology for measuring lift-off, so the lach of agreement in the results can be mostly attributed to broadband chemiluminescence imaging, as sensitivity plays a major role. Nonetheless, this type of imaging it still useful to study a time resolved lift-off length, although new methodologies like intensified high speed cameras are recommended for future experiments.

- To study the effect of parametric ambient conditions on lift-off length, $\mathrm{OH}^{*}$ chemiluminescence imaging is used, because of the reasons stated before.
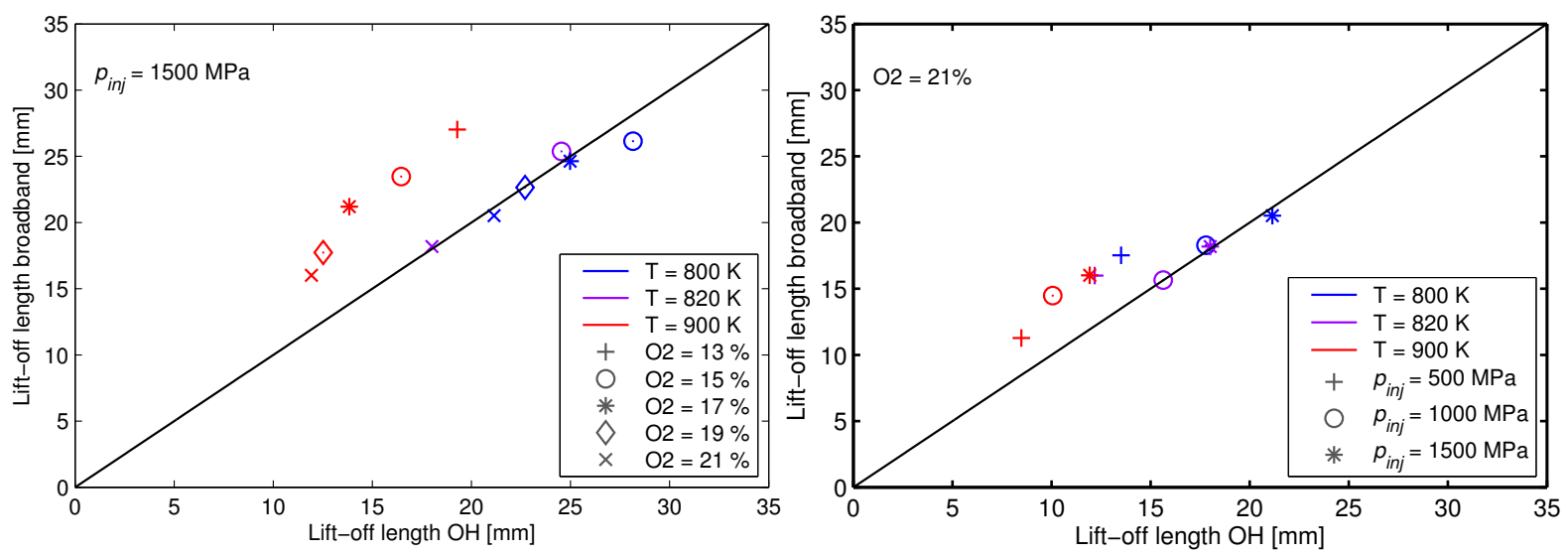

Fig. 7: Lift-off measurements for all conditions tested. Horizontal axis correspond to $\mathrm{OH}^{*}$ imaging and vertical axis to broadband chemiluminescence. Left plot corresponds to variations of oxygen concentration, while the right plot to injection pressures. Black solid line represents $y=x$.

\subsubsection{Impact of operating conditions on lift-off length}

It was previously said that lift-off is a good indicator of how well air and fuel are mixed before combustion. As others authors have described in their results [27, 29, 37, 38], increasing density, ambient temperature and oxygen concentration will reduce lift-off length, because 
they improve evaporation and mixing. On the other hand, increasing injection pressure correspond in an increment in spray velocity, and as describe by Peters [39], lift-off is the region where the stabilization between of jet velocity and flame front speed occurs, so lift-off length increases, this effect has also been observed experimentally [20, 26].

In Fig. 8 is possible to observe how test conditions affect lift-off length. LOL is plotted against different oxygen concentrations, colors and symbols correspond to variations in temperature and injection pressure, respectively. In addition, two images (A and B) are also presented to compare flame uniformity for different conditions. From the results, its possible to observe that at low ambient temperature and oxygen concentrations, injection pressure seems to play a bigger role in the lift-off length. As expected, with increasing temperature and oxygen concentration, lift-off length is reduced. Also at higher temperature, flame near LOL was more uniform (see Fig. 8, images A and B) and showed less deviation through each repetition, this was also true with increasing oxygen concentration as well.

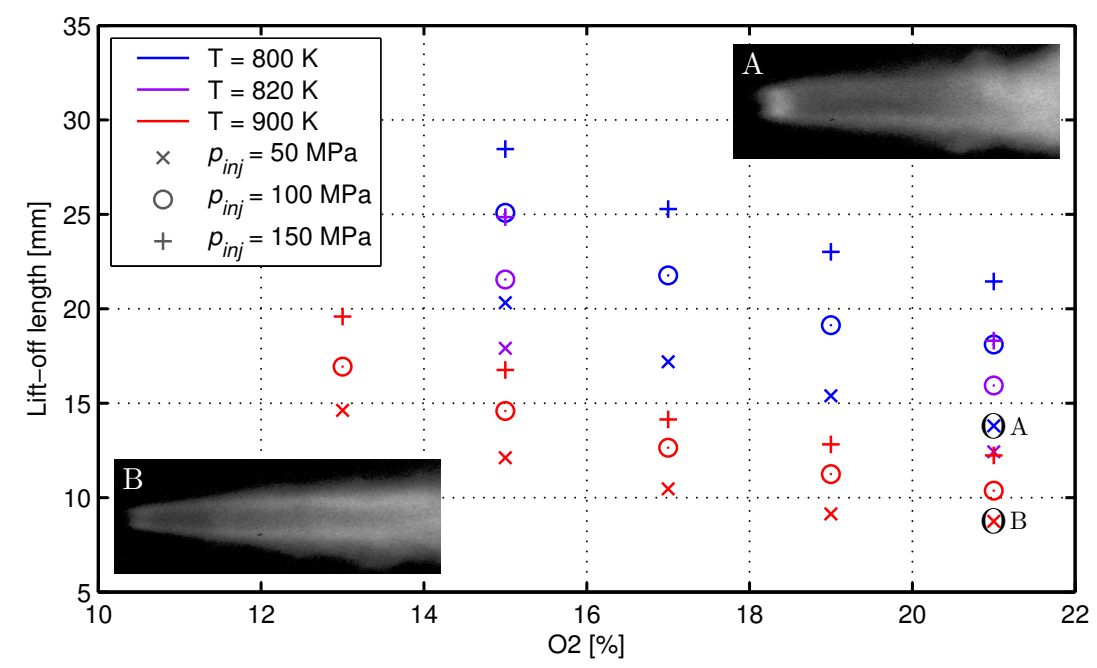

Fig. 8: Effect of ambient conditions on ignition lift-off length, but constant density of $22.8 \mathrm{~kg} / \mathrm{m}^{3}$.

\subsubsection{Time dependent lift-off}

As seen in Fig. 7. $\mathrm{OH}^{*}$ and broadband chemiluminescence lift-off measurements showed significant deviation. Still, results from the latter methodology are useful to observe flame stability through time, and study how certain parameters play a role in its stabilization. In order to measure a time-dependent lift-off length and to simplify comparison between conditions, a rolling average procedure was used to obtain the mean values between repetitions for each condition tested, following the methodology proposed by Payri et al [40]. Accordingly, in Fig. 9 time dependent lift-off measured through broadband chemiluminescence is plotted. From the two graphs, it is possible to conclude that at lower oxygen concentration and injection pressure, flame propagation is slower once injection has ended (note the slope of the curve), temperature seems not to affect this phenomenon. Because the mixture ignites in one or several locations, transients at the beginning of the curve present different forms, but the general trend is that lift-off gets closer to the injector, then is stable during the injection period, and the flame propagates at a fixed rate (constant slope) once injection has ended. 
Raúl Payri, F.J. Salvador, Julien Manin, Alberto Viera; Diesel ignition delay and lift-off length through different methodologies using a multi-hole injector. Applied Energy, 2015, 162, 541-550.
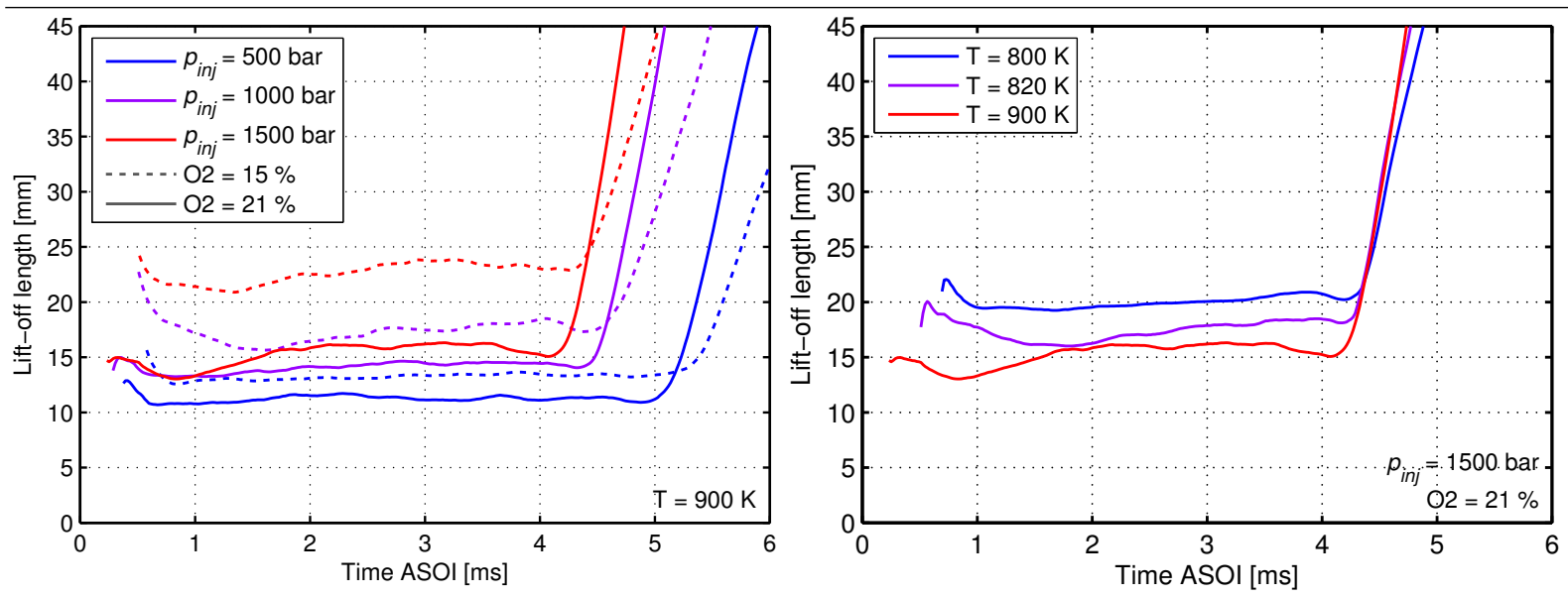

Fig. 9: Time dependant lift-off measured through broadband chemiluminescence for different ambient conditions, but constant density of $22.8 \mathrm{~kg} / \mathrm{m}^{3}$.

\subsection{Comparison with single orifice nozzle}

The results obtained with the 3-hole nozzle are comparable to the ones showed by Benajes et al. [20] for the single hole, because both injectors are analog in technology and characteristics. The Spray B injector was developed with the same orifice specifications as Spray A, in order to understand how the internal geometry of a multi orifice injector affected spray development. As stated before, all the data for both injectors can be found on the ECN website [11].
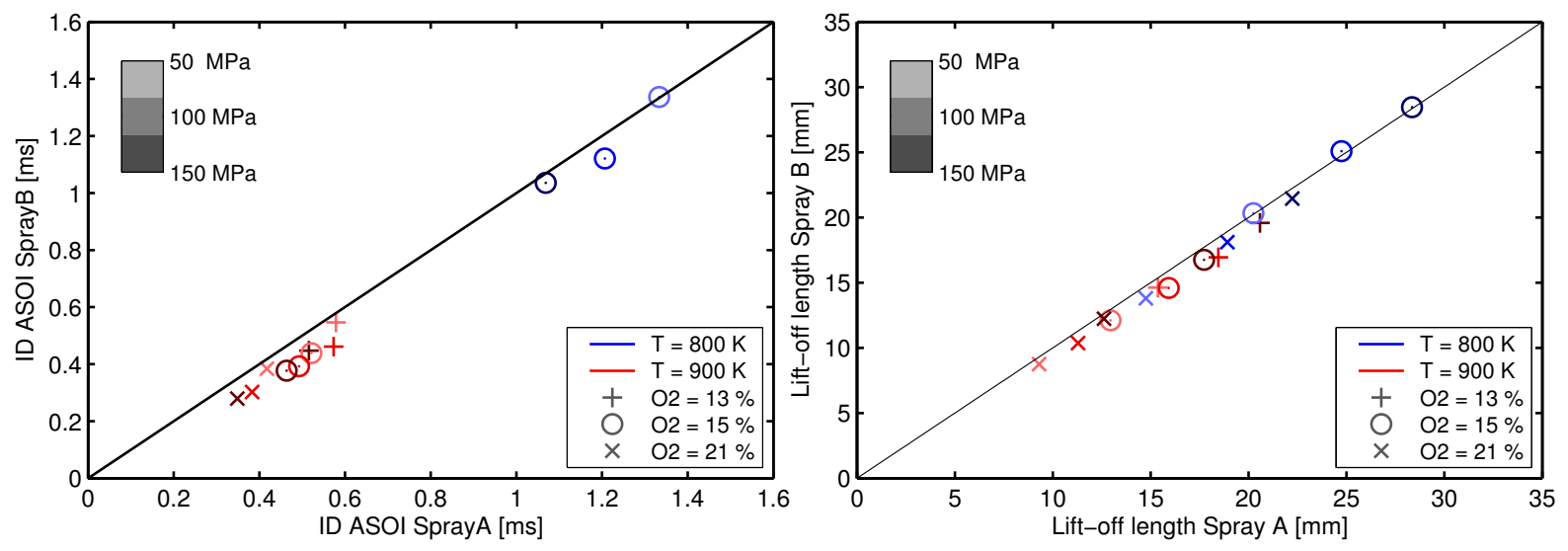

Fig. 10: Ignition delay (left) and lift-off length (right) comparison between a single orifice (Spray A) and multi orifice (Spray B) injectors. Color gradients correspond to injection pressure variations, lightest color is $50 \mathrm{MPa}$ going to the darkest color $150 \mathrm{MPa}$. Black solid line represents $y=x$.

In Fig. 10 comparisons between the two injectors are presented, please note that only common conditions are compared. On the left plot, Spray B shows shorter ignition delays for most of the conditions. This can be attributed to the temperature differences across the chamber, as the sprays do not penetrate in the same direction. The orifice of interest in Spray $\mathrm{B}$ was pointing downwards towards a region of the chamber closer to the inlet, and as shown in previous results, ambient temperature is a key factor in the development of the combustion, although still the differences were very small. In the right part of the figure, lift-off length results show a similar trend as ignition delay, Spray B showed shorter LOL in most of the 
conditions compared, but even though temperature plays a big role in the result of lift-off as well, the differences between injectors was smaller than in the previous case. This can be attributed to the fact that ignition delay is more related to fuel chemistry, on the other hand, LOL is also driven by flame speed.

\subsection{Statistical analysis}

Thanks to the wide range of conditions tested it is possible to perform a statistical analysis . Empirical correlations have been used by many researchers to describe the relationship between conditions and both ignition delay, reviews of these correlations are presented by Ramos [41] and Heywood [42]. For ignition delay, many authors have used derived versions of Arrhenius equation, as his original equation only describes the dependency of reaction rates on temperature, adding the influence of other parameters such as oxygen concentration [34, 38], injection pressure [18, 32, 43], or density [20, 27, 34]. In accordance with the work of previous authors, the following equation describing the dependency of ignition delay under changing conditions is proposed:

$$
I D \propto \exp \left(\frac{A}{T}\right) \cdot \rho_{a m b}^{a} \cdot \Delta p_{i n j}^{b} \cdot O_{2 \%}^{c}
$$

Where ID correspond to ignition delay, $T$ to ambient temperature, $\rho_{a m b}$ to ambient density, $\Delta p_{i n j}$ is the fuel pressure drop through the nozzle's orifice, estimated to be the difference between injection and chamber pressure, and finally $\mathrm{O}_{2} \%$ is oxygen concentration. For liftoff length, although Arrhenius-derived equations have also been widely used [27], in order to compared the results of the coefficient of the approximation with the analog single orifice injector from the ECN dataset, the same approach used by Benajes et al. [20] is proposed, so an exponential equation is defined:

$$
L O L \propto T^{a} \cdot \rho_{a m b}^{b} \cdot\left(\sqrt{2 \frac{\Delta p_{i n j}}{\rho_{\text {fuel }}}}\right)^{c} \cdot O_{2 \%}^{d}
$$

Where the term in parenthesis correspond to the theoretical velocity of the fuel at the nozzle exit. In tables 3 and 4 results from equations 1 and 2 are respectively presented. Additionally, coefficients obtained from the regressions by Benajes et al. [20] for the single orifice are included. Because results shown in Fig. 5 showed excellent agreement for high temperature, ignition delays values for lower ambient densities have been added to the Schlieren regression, in order to quantify the impact of density.

Table 3: Empirical correlation results for ignition delay. Coefficient obtained by Benajes et al. [20] for Spray A are reported for reference and comparison.

\begin{tabular}{ccccccc}
\hline Injector & Method & $\mathbf{A}$ & $\mathbf{a}$ & $\mathbf{b}$ & $\mathbf{c}$ & $\mathbf{R}^{2}$ \\
\hline \multirow{2}{*}{ Spray B } & Broadband & 6444 & -1.39 & -0.26 & -1.38 & 95.7 \\
& Schlieren & 7652 & -1.40 & -0.19 & -0.73 & 99.2 \\
\multirow{2}{*}{ Spray A } & Broadband & 7216 & -1.25 & -0.09 & -0.93 & 98.0 \\
& Schlieren & 7523 & -1.35 & -0.09 & -0.51 & 97.9 \\
\hline
\end{tabular}


Raúl Payri, F.J. Salvador, Julien Manin, Alberto Viera; Diesel ignition delay and lift-off length through different methodologies using a multi-hole injector. Applied Energy, 2015, 162, 541-550.

Table 4: Empirical correlation results for lift-off length. Coefficient obtained by Benajes et al. [20] for Spray A are reported for reference and comparison.

\begin{tabular}{cccccc}
\hline Injector & $\mathbf{a}$ & $\mathbf{b}$ & $\mathbf{c}$ & $\mathbf{d}$ & $\mathbf{R}^{2}$ \\
\hline Spray B & -4.45 & - & 0.59 & -1.02 & 99.2 \\
Spray A & -3.89 & -1 & 0.54 & -1 & 99.5 \\
\hline
\end{tabular}

Ignition delay correlation for Spray B obtained with Schlieren imaging showed good agreement with those obtain for Spray A. The broadband chemiluminescence coefficients for temperature, injection pressure and oxygen concentration for Spray B are not matching the Spray A coefficients, which supports the statement that this methodology is too sensitive to light variations and conditions, yet high value of $\mathrm{R}^{2}$ for both methodologies confirm the excellent repeatability and reliability of the results gathered. On the other hand, lift-off length coefficients also showed excellent agreement, confirming the results of the experimental comparison presented in Fig. 10.

\section{Conclusions}

Ignition delay and lift-off length measurements were carried out in a constant-pressure flow facility. Both parameters were measured via two different methodologies: Ignition delay obtained with broadband chemiluminescence and Schlieren imaging, LOL measured with $\mathrm{OH}^{*}$ and broadband chemiluminescence. For the study a 3 hole injector from the ECN, and a single component fuel (n-Dodecane) were used. A wide range of test conditions were implemented, including variations in oxygen concentration, injection pressure, ambient temperature, and density. Additionally, results were compared with a single hole injector also from the ECN, with similar orifice specifications. Empirical correlations were obtained and also compared with this injector. The results showed good repeatability and consistency with what found in the literature. In addition, good agreement with experimental results from other authors has been observed when comparing single and multi hole nozzle, highlighting the reliability of the data. The following conclusion can be drawn:

1. Ignition delay showed minor differences measured via the two methodologies. A different approach, due to shorter exposure time, was used to process broadband chemiluminescence results, to counter saturation due to combustion in the images gathered. This approach proved to give accurate results when compared to ignition delay via Schlieren imaging for the conditions tested.

2. On the effect of test conditions on ignition delay, the trend obtained is consistent to what was found in the literature: increasing density, temperature, injection pressure and oxygen concentration, all reduce ignition delay; the former two parameters having a bigger impact on ignition than the latter two.

3. Broadband chemiluminescence lift-off length results obtained are not comparable with $\mathrm{OH}^{*}$ chemiluminescence for the configuration used, because soot formation occurs downstream in the spray. To minimize this, a very low threshold value was used, but still results between methodologies showed big dispersion, as $\mathrm{CH}^{*}$ chemiluminescence was not capture due to low sensitivity. Nonetheless broadband chemiluminescence allows to 
study flame stability through time. From this findings, for lower injection pressures and oxygen concentration, flame propagation was lower once the injection ended. Temperature did not affect this phenomenon. Also flame propagation once the injection ended was observed at a fixed rate.

4. Lift-off variations throughout test conditions also showed good agreement with results from the literature: lift-off length decreases with increasing ambient temperatures and oxygen concentrations, or decreasing injection pressure.

5. From an experimental point of view, nozzle geometry had a small effect on ignition delay and lift-off length. Due to the fact that sprays penetrate in different directions, multi hole nozzle was directed towards a region of the chamber with higher temperature, thus explaining the difference in smaller ignition delays and shorter lift-off lengths. This highlights the importance of temperature variations along the chamber for spray and combustion development.

6. Good agreement was found on the coefficients of the empirical correlations calculated when compared to the single hole injector, specially for ignition delay measured with Schlieren imaging and lift-off length through $\mathrm{OH}^{*}$ chemiluminescence. This supports the results obtained when comparing the two different injectors analog in technology and geometry characteristics, and shows that variations in test conditions have a similar impact on ignition delay and lift-off regardless nozzle orifice configuration.

7. High $\mathrm{R}^{2}$ obtained in the empirical correlations shows the good repeatability and reliability of results gathered.

\section{Acknowledgments}

This work was sponsored by "Ministerio de Economía y Competitividad" of the Spanish Government in the frame of the Project "Comprensión de la influencia de combustibles no convencionales en el proceso de injección y combustión tipo Diesel”, Reference TRA2012-36932. Additionally, the optical equipment used for the project was purchased with funding from Ministerio de Economía y Competitividad FEDER-ICTS-2012-06.

The authors would finally like to thank Jose Enrique Del Rey and Borja Hurtado for their collaboration in the setup of the experiments and laboratory work.

\section{References}

[1] M. P. B. Musculus, P. C. Miles, L. M. Pickett, Conceptual models for partially premixed low-temperature diesel combustion, Progress in Energy and Combustion Science 39 (2013) 246-283.

[2] S. Han, J. Kim, C. Bae, Effect of air-fuel mixing quality on characteristics of conventional and low temperature diesel combustion, Applied Energy 119 (2014) 454-466.

[3] F. Zhang, R. Yu, X.-S. Bai, Effect of split fuel injection on heat release and pollutant emissions in partially premixed combustion of PRF70/air/EGR mixtures, Applied Energy 149 (2015) 283-296.

[4] C. Gong, M. Jangi, X.-S. Bai, Large eddy simulation of $n$-dodecane spray combustion in a high pressure combustion vessel, Applied Energy 136 (2014) 373-381.

[5] M. A. Jemni, G. Kantchev, M. S. Abid, Influence of intake manifold design on in-cylinder flow and engine performances in a bus diesel engine converted to LPG gas fuelled, using CFD analyses and experimental investigations, Energy 36 (2011) 2701-2715. 
[6] S. Bari, I. Saad, Effect of guide vane height on the performance and emissions of a compression ignition (CI) engine run with biodiesel through simulation and experiment, Applied Energy 136 (2014) 431-444.

[7] P. Deng, Q. Jiao, R. D. Reitz, Z. Han, Development of an improved spray/wall interaction model for diesellike spray impingement simulations, Atomization and Sprays 25 (2015) 587-615.

[8] C. Chartier, U. Aronsson, O. Andersson, R. Egnell, B. Johansson, Influence of jet-jet interactions on the lift-off length in an optical heavy-duty DI diesel engine, Fuel 112 (2013) 311-318.

[9] G. Lequien, E. Berrocal, Y. Gallo, A. T. e Mello, O. Andersson, B. Johansson, Effect of jet-jet interactions on the liquid fuel penetration in an optical heavy-duty DI diesel engine, SAE Paper 2013-01-1615 (2013).

[10] Y. Jung, J. Manin, S. Skeen, L. M. Pickett, Measurement of liquid and vapor penetration of diesel sprays with a variation in spreading angle, SAE Paper 2015-01-0946 (2015).

[11] ECN, Engine Combustion Network, Online, 2015. URL: WwW . sandia . gov/ecn/

[12] M. Meijer, B. Somers, J. Johnson, J. Naber, S.-Y. Lee, L. M. Malbec, G. Bruneaux, L. M. Pickett, M. Bardi, R. Payri, T. Bazyn, Engine Combustion Network (ECN): characterization and comparison of boundary conditions for different combustion vessels., Atomization and Sprays 22 (2012) 777-806.

[13] M. Bardi, R. Payri, L. M. Malbec, G. Bruneaux, L. M. Pickett, J. Manin, T. Bazyn, C. Genzale, Engine Combustion Network: comparison of spray development, vaporization, and combustion in different combustion vessels, Atomization and Sprays 22 (2012) 807-842.

[14] A. L. Kastengren, F. Z. Tilocco, C. F. Powell, J. Manin, L. M. Pickett, R. Payri, T. Bazin, Engine Combustion Network (ECN): Measurements of nozzle diameter and hydraulic behavior, Atomization And Sprays 22 (2012) 1011-1052.

[15] R. S. Baert, P. J. Frijters, B. Somers, C. C. Luijten, W. de Boer, Design and operation of a high pressure, high temperature cell for HD Diesel spray diagnostics: guidelines and results, SAE Paper 2009-04-20 (2009).

[16] D. Siebers, Liquid-phase fuel penetration in Diesel sprays, SAE Paper 980809 (1998).

[17] S. E. Parrish, R. Zink, Development and Application of Imaging System to Evaluate Liquid and Vapor Envelopes of Multi-Hole Gasoline Fuel Injector Sprays under Engine-like Conditions, Atomization and Sprays 22 (2012) 647-661.

[18] R. Payri, J. M. García-Oliver, M. Bardi, J. Manin, Fuel temperature influence on diesel sprays in inert and reacting conditions, Applied Thermal Engineering 35 (2012) 185-195.

[19] J. E. Dec, C. Espey, Chemiluminescence imaging of autoignition in a DI Diesel engine, SAE Paper 982685 (1998).

[20] J. Benajes, R. Payri, M. Bardi, P. Martí-Aldaraví, Experimental characterization of Diesel ignition and lift-off length using a single-hole ECN injector, Applied Thermal Engineering 58 (2013) $554-563$.

[21] P. M. Lillo, L. M. Pickett, Diesel spray ignition detection and spatial/temporal correction, SAE Paper 201201-1239 (2012).

[22] L. M. Pickett, S. Kook, T. C. Williams, Visualization of diesel spray penetration, cool-flame, ignition, hightemperature combustion, and soot formation using high-speed imaging, SAE Paper 2009-01-0658 (2009).

[23] G. S. Settles, Schileren and Shadowgraphy Techniques. Visualizing Phenomena in Transparent Media, Springer, 2006.

[24] J. V. Pastor, R. Payri, J. M. Garcia-Oliver, J.-G. Nerva, Schlieren Measurements of the ECN-Spray A Penetration under Inert and Reacting Conditions, SAE Paper 2012-01-0456 (2012).

[25] P. Lax, M. Terrell, Calculus With Applications, Undergraduate Texts in Mathematics, Springer New York, 2013.

[26] D. L. Siebers, B. Higgins, Flame lift-off on direct-injection diesel sprays under quiescent conditions, SAE Paper 2001-01-0530 (2001).

[27] L. M. Pickett, D. L. Siebers, C. A. Idicheria, Relationship between ignition processes and the lift-off length of diesel fuel jets, SAE Paper 2005-01-3843 (2005).

[28] A. Gaydon, The Spectroscopy of Flames, Springer Netherlands, 2012.

[29] B. Higgins, D. Siebers, Measurement of the flame lift-off location on di diesel sprays using oh chemiluminescence, SAE Paper 2001-01-0918 (2001).

[30] J. E. Dec, A conceptual model of DI Diesel combustion based on laser-sheet imaging., SAE Paper 970873 (1997).

[31] R. Payri, J. P. Viera, Y. Pei, S. Som, Experimental and numerical study of lift-off length and ignition delay of a two-component diesel surrogate, Fuel 158 (2015) 957 - 967.

[32] R. Payri, F. Salvador, J. Gimeno, J. De la Morena, Effects of nozzle geometry on direct injection Diesel engine 
combustion process, Applied Thermal Engineering 29 (2009) 2051-2060.

[33] V. Macian, R. Payri, S. Ruiz, M. Bardi, A. H. Plazas, Experimental study of the relationship between injection rate shape and Diesel ignition using a novel piezo-actuated direct-acting injector, Applied Energy 118 (2014) 110-113.

[34] M. Lapuerta, J. Sanz-Argent, R. R. Raine, Ignition Characteristics of Diesel Fuel in a Constant Volume Bomb under Diesel-like Conditions. Effect of the Operation Parameters, Energy \& Fuels 28 (2014) 5445-5454.

[35] R. Petrucci, F. Herring, J. Madura, C. Bissonnette, General Chemistry Principles and Modern Applications, Pearson eText, Pearson Prentice Hall, 2010.

[36] T. Bazyn, C. Koci, The effect of jet spacing on the combustion characteristics of Diesel sprays, Thiesel (2014).

[37] C. A. Idicheria, L. M. Pickett, Effect of EGR on diesel premixed-burn equivalence ratio, Proceedings of the Combustion Institute 31 (2007) 2931 - 2938.

[38] S. Aggarwal, A review of spray ignition phenomena: present status and future research, Progress in Energy and Combustion Science 24 (1998) 565 - 600.

[39] N. Peters, Turbulent Combustion, Cambridge Monographs on Mechanics, Cambridge University Press, 2000.

[40] R. Payri, J. Gimeno, M. Bardi, A. H. Plazas, Study liquid length penetration results obtained with a direct acting piezo electric injector, Applied Energy 106 (2013) 152-162.

[41] J. I. Ramos, Internal Combustion Engine Modelling, Hemisphere Publishing Corporation, 1989. ISBN 089116-157-0.

[42] J. Heywood, Internal combustion engine fundamentals, Automative technology series, McGraw-Hill Education, 1988.

[43] R. Payri, F. Salvador, J. Gimeno, J. D. la Morena, Influence of injector technology on injection and combustion development, part 2: Combustion analysis, Applied Energy 88 (2011) 1130 - 1139. 